\title{
Application of selective extraction to the study of iron species present in diet and rat gastrointestinal tract contents
}

\author{
BY ROBERT J. SIMPSON, SANJIV SIDHAR AND TIMOTHY J. PETERS \\ Department of Clinical Biochemistry, King's College School of Medicine and Dentistry, Bessemer \\ Road, London SE5 $9 P J$
}

(Received 21 December 1990-Accepted 19 June 1991)

\begin{abstract}
Iron speciation in rodent diet and rat gastrointestinal tract lumen during dietary digestion and absorption was investigated with a novel selective extraction technique. Five Fe fractions were identified, namely exchangeable (soluble in $1 \mathrm{M}$-magnesium chloride), carbonate-bound (soluble in mild acid), oxide-bound (soluble in hydroxylamine -acetic acid), organic-bound (soluble after treatment with peroxide in nitric acid) and residual. Fe from the pelleted diet was mobilized by rat stomach to the exchangeable fraction, then redistributed to the carbonate- and oxide-bound fractions on passage through the proximal small intestine. In vitro incubation of diet with hydrochloric acid failed to mimic the in vivo effect of the stomach. In vitro neutralization of stomach contents with bicarbonate was found to produce a similar effect on Fe speciation to that seen when diet passed the proximal small intestine in vivo. Comparison of ${ }^{59} \mathrm{Fe}$ speciation in extrinsically labelled diet with endogenous Fe speciation showed that extrinsic labelling does not uniformly label all endogenous species. The experiments suggest that selective extraction may provide a useful approach to the study of $\mathrm{Fe}$ species present in diets, in vitro digestions and gastrointestinal contents.
\end{abstract}

Iron speciation: Selective extraction technique : Rodent diet

In vitro techniques for assessing iron bioavailability are potentially of great interest for improving Fe nutrition (Narisingha Rao \& Prabhavathi, 1978; Lock \& Bender, 1980; Miller et al. 1981; Fairweather-Tait, 1987). Such techniques are ideally based on combining knowledge of Fe chemistry with the physiological and biochemical processes of digestion and absorption. Unfortunately, current understanding of the chemistry of Fe within the small intestine during absorption is limited by the large number of potential ligands present and the non-equilibrium state of complexation that probably occurs during absorption. Approaches such as dialysis (Miller et al. 1981), solubility (Jacobs \& Greenman, 1969; Lock \& Bender, 1980), ultrafiltration (Glover \& Jacobs, 1971), binding to chelators (Reddy et al. 1986) and kinetics of reaction with chelators (Simpson \& Peters, 1990) have been used to try to distinguish $\mathrm{Fe}$ species present during in vivo or in vitro digestion of diets.

We set out to apply a new technique of selective extraction (Tessier et al. 1979) to the determination of $\mathrm{Fe}$ species present in a rodent diet during digestion in the rat gastrointestinal tract and to investigate the usefulness of this technique in comparing Fe species in in vitro model digestion with those present in vivo. The technique is also applied to comparing the ${ }^{59} \mathrm{Fe}$ speciation of extrinsically labelled diet with the endogenous $\mathrm{Fe}$ speciation.

METHODS AND MATERIALS

Diet was obtained from Labsure (Manea, Cambridgeshire, UK; diet ERD) and consisted of maize, wheat, white fish meal, wheat germ, Brewer's yeast and a mineral and vitamin supplement including $50 \mathrm{mg}$ ferrous sulphate $/ \mathrm{kg}$ (manufacturer's data; further details are 
given in Simpson \& Peters, 1990). The diet contained (mean (with SE) for three determinations) $3.1(0 \cdot 3) \mathrm{nmol}$ non-haem $\mathrm{Fe} / \mathrm{mg}$ diet with no detectable haem $\mathrm{Fe}(<$ $0.1 \mathrm{nmol}$ ). Rats (male, Sprague-Dawley) were fed ad lib. on this diet from weaning until they weighed $250-400 \mathrm{~g}$. Rats were killed by cervical dislocation and the stomach and small intestine were removed. The small intestine was divided into three equal portions and the contents of these and the stomach were collected individually and stored at $-20^{\circ}$, then analysed for Fe by selective extraction using a method based on that of Tessier et al. (1979). Samples from each rat were analysed individually except in the case of proximal intestine contents, where the samples were too small to be analysed and were therefore combined and a single analysis was performed. All glassware was soaked in nitric acid $(140 \mathrm{ml} / \mathrm{l})$ and rinsed repeatedly in deionized water.

Fe was determined electrothermally with a Perkin-Elmer atomic absorption spectrophotometer (model no. 2380) with an HGA 500 furnace (Selden \& Peters, 1979). Solid samples were analysed after wet ashing in $\mathrm{HNO}_{3}-$ sulphuric acid $(1: 1, \mathrm{v} / \mathrm{v})$. Samples were diluted into a linear range and quantified with both internal and external standards. Nonhaem Fe was determined as described in Simpson \& Peters (1990).

\section{Sequential extraction procedure}

Volumes given are for $1 \mathrm{~g}$ samples. Each fraction was the supernatant fraction obtained after $30 \mathrm{~min}$ centrifugation at $10000-12000 \mathrm{~g}$ combined with a wash obtained by mixing the pellet with $8 \mathrm{ml}$ water and recentrifuging. The remaining pellet was subjected to the next extraction step.

Exchangeable fraction: incubate for $1 \mathrm{~h}$ with $8 \mathrm{ml} 1 \mathrm{M}$-magnesium chloride with continuous agitation at room temperature. Carbonate-bound fraction: incubate for $4 \mathrm{~h}$ with $8 \mathrm{ml} 1 \mathrm{M}$-sodium acetate ( $\mathrm{pH} 5 \cdot 0$, adjusted with acetic acid) with continuous agitation at room temperature. Oxide-bound fraction: incubate with $20 \mathrm{ml} 0.04 \mathrm{M}$-hydroxylamine hydrochloride in acetic acid $(250 \mathrm{ml} / \mathrm{l})$ at $95^{\circ}$ for $16 \mathrm{~h}$. Fraction bound to organic matter: incubate with $3 \mathrm{ml} 0.02 \mathrm{M}-\mathrm{HNO}_{3}$ and $5 \mathrm{ml}$ hydrogen peroxide $(300 \mathrm{ml} / \mathrm{l}$; pH 2, adjusted with $\mathrm{HNO}_{3}$ ) for $2 \mathrm{~h}$ at $85^{\circ}$ with occasional agitation, add a further $3 \mathrm{ml} \mathrm{H}_{2} \mathrm{O}_{2}(300 \mathrm{ml} / \mathrm{l}$; $\mathrm{pH} 2$ ) and heat for a further $3 \mathrm{~h}$ at $85^{\circ}$. The mixture was cooled, $5 \mathrm{ml} 3.2 \mathrm{M}$-ammonium acetate in $\mathrm{HNO}_{3}(200 \mathrm{ml} / \mathrm{l})$ added, then diluted to $20 \mathrm{ml}$ and agitated continuously for $30 \mathrm{~min}$. Residual fraction: the final pellet. The total Fe in all five fractions was summed and the content of each fraction expressed as a percentage of the total.

The exchangeable fraction includes soluble Fe complexes. The carbonate-bound fraction represents $\mathrm{Fe}$ bound to insoluble ligands with a $\mathrm{p} K$ of 5 or more. The oxide-bound fraction includes $\mathrm{Fe}$ bound in a form susceptible to reduction or bound to ligands with a $\mathrm{p} K$ of 2 or more, or both. The organic-bound fraction includes insoluble haem-Fe as well as $\mathrm{Fe}$ bound to other ligands degraded by oxidation. The residual fraction represents Fe bound to ligands not degraded by the previously described procedures. The names used to describe the fractions are taken from the soil analysis method (Tessier et al. 1979) and are therefore somewhat arbitrary in the context of the application to diet or intestinal contents. These names are retained here for brevity and to avoid confusion.

\section{Modelling of speciation and effects of digestion and extrinsic labelling of diet}

In vitro acidification of the diet was performed by adding 2-3 vol. water to powdered diet, then sufficient hydrochloric acid (as $\mathrm{M}$ or $10 \mathrm{M}$ solutions) to obtain the appropriate $\mathrm{pH}$. The mixture was vigorously mechanically shaken for $15 \mathrm{~min}$ then analysed for Fe speciation as described previously. Stomach contents were neutralized by addition of 2 vol. water then $0.5 \mathrm{M}$-sodium bicarbonate (approximately $800 \mu \mathrm{l} / \mathrm{g}$; final $\mathrm{pH} 6.5$ ). Neutralized stomach contents were analysed for $\mathrm{Fe}$ speciation as described previously. 


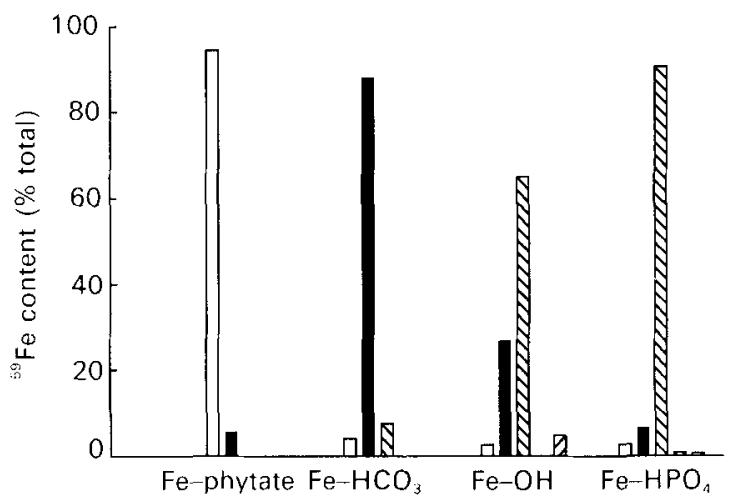

Fig. 1. Analysis of model iron mixtures by sequential extraction. Each analysis is displayed as a histogram with five fractions: exchangeable $(\square)$, bound to carbonates $(\square)$, bound to oxides ( $($ ), bound to organic matter ( $\forall$ ), residual ( For details of procedures, see pp. $438-439$

Model Fe solutions were prepared as follows : $100 \mu 110 \mathrm{~mm}$-ferric chloride in $10 \mathrm{mM}-\mathrm{HCl}$ was mixed with $0.5 \mu \mathrm{Ci}{ }^{59} \mathrm{FeCl}_{3}$, then $100 \mu \mathrm{l}$ portions of (a) $0.1 \mathrm{M}-\mathrm{NaHCO}_{3}$; (b) $10 \mathrm{~mm}$ sodium phytate in $10 \mathrm{~mm}$-sodium HEPES (4-hydroxylpiperazine ethanesulphonic acid) $0.15 \mathrm{M}$-sodium chloride ( $\mathrm{pH} \mathrm{7.4)}$; (c) $0.1 \mathrm{M}$-sodium phosphate $(\mathrm{pH} 7.0)$ or (d) $10 \mathrm{~mm}$ sodium HEPES $0.15 \mathrm{M}-\mathrm{NaCl}(\mathrm{pH} \mathrm{7.4)}$ were added. Subsequent additions of $100 \mu \mathrm{l} 40 \mathrm{~mm}-$ sodium HEPES-0.2 M-NaCl (pH 7.4) were made to solutions (b) and (c) and $10 \mu 11 \mathrm{M}$ sodium hydroxide was added to solution (d). All four samples were left for $48 \mathrm{~h}$ at room temperature (approximately $20^{\circ}$ ) then analysed by selective extraction as described previously. ${ }^{59} \mathrm{Fe}$ in each fraction was determined by counting in a Beckman gamma-7000 (Beckman Instruments Inc., Fullerton, CA, USA).

Diet was extrinsically labelled with ${ }^{59} \mathrm{Fe}$ by hydrating $2 \mathrm{~g}$ diet with $5 \mathrm{ml}$ water, adding $1 \mu \mathrm{Ci}{ }^{59} \mathrm{FeCl}_{3}$ (Amersham International, Amersham, Bucks.), mixing thoroughly, then drying in an oven at $60^{\circ}$. One group of rats was given $1 \mu \mathrm{Ci}^{59} \mathrm{FeCl}_{3}$ in $1 \mathrm{ml} 10 \mathrm{mM}-\mathrm{HCl}$ by stomach tube then killed $1 \mathrm{~h}$ later (food and water were given ad lib. during this period). Contents of stomach and three equal portions of small intestine were collected and analysed by sequential extraction as described previously. The segments of gastrointestinal tract were washed with $10 \mathrm{ml} 0.15 \mathrm{M}-\mathrm{NaCl}$, then washings, intestinal segments and rat carcasses were counted for ${ }^{59} \mathrm{Fe}$.

\section{Statistical analysis}

Comparison of $\mathrm{Fe}$ extraction into all five fractions in the different gastrointestinal locations and diets from the ${ }^{59} \mathrm{Fe}$ labelling and the total $\mathrm{Fe}$ speciation experiments was performed simultaneously by multiple analysis of variance using the SPSS-PC + program (SPSS Inc., Chicago, IL, USA).

\section{RESULTS}

Model $\mathrm{Fe}$ solutions were investigated for $\mathrm{Fe}$ speciation using the selective extraction technique (Fig. 1). Four possible species which could be encountered in diet or gastrointestinal tract contents, or both, show distinctive fractionation patterns. However, it is clear that many different Fe species could give similar patterns to that of, for example, Fe phytate complex. The mixtures shown in Fig. 1 demonstrate examples of Fe species that are predominantly present in different fractions of the extraction process. The pattern seen with $\mathrm{Fe}-\mathrm{OH}^{-}$suggests the presence of more than one species in this crude Fe precipitate, 


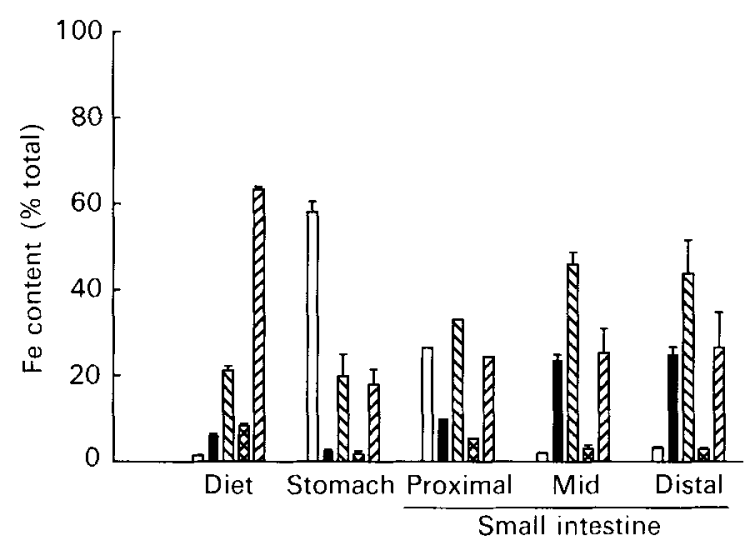

Fig. 2. Iron speciation of diet and gastrointestinal contents by sequential extraction. Commercial rodent diet and contents of the stomach and proximal, mid and distal sections of the small intestines of rats fed ad lib. on the diet were analysed by sequential extraction. Fractions are: exchangeable $(\square)$, bound to carbonates ( $\square$ ), bound to oxides $(\Theta)$, bound to organic matter $(\otimes)$, residual $(\mathbb{Z})$. Values are means with their standard errors represented by vertical bars for four determinations, except for the proximal contents, which show an analysis of the combined proximal contents of four rats. For details of procedures, see pp. 438-439.

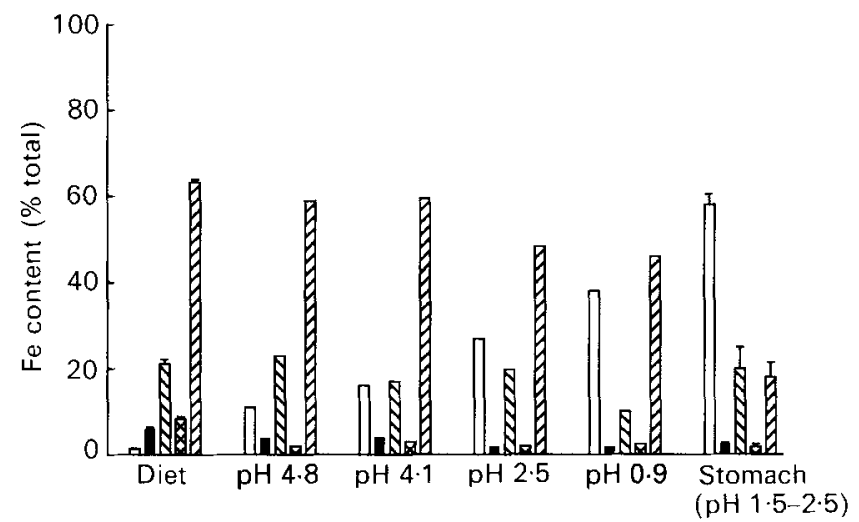

Fig. 3. Effect of in vitro acid treatment on iron speciation in the diet. The diet was hydrated and adjusted to the indicated $\mathrm{pH}$ with hydrochloric acid, shaken for $15 \mathrm{~min}$ and then analysed by sequential extraction. The hydrated diet had a pH of approximately 6.5. Fractions are : exchangeable ( $\square$ ), bound to carbonates $(\square)$, bound to oxides $(\Theta)$, bound to organic matter ( $\otimes)$, residual ( $\triangle)$. Values for diet and stomach contents are those shown in Fig. 2. Values are means with their standard errors represented by vertical bars for four determinations. For details of procedures, see pp. $438-439$.

Fig. 2 shows the speciation pattern of the diet and the changes occurring during passage down the rat gastrointestinal tract. Normal feeding was allowed in order to investigate physiological speciation of $\mathrm{Fe}$ in rat intestine. The main effect of the stomach is a mobilization of $\mathrm{Fe}$ from the residual fraction to the exchangeable fraction. The identity of the residual fraction is not known but it may represent Fe bound to dietary fibre. Passage of diet through the proximal small intestine results in a redistribution of $\mathrm{Fe}$ to the carbonate and oxide-bound fractions. No further change occurs distally to the mid small intestine. These findings are consistent with the exchangeable fraction being the fraction that contains the bioavailable Fe species, since Fe absorption is highly localized to the proximal small intestine (Brown \& Justus, 1958; Wheby \& Crosby, 1963; Becker et al. 1979; Johnson 


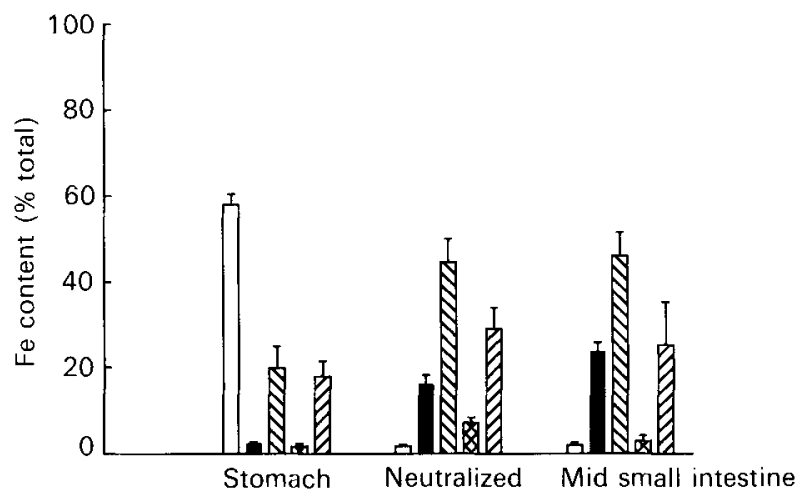

Fig. 4. Effect of in vitro neutralization on iron speciation in stomach contents. Rat stomach contents were neutralized by addition of $0.5 \mathrm{M}$-sodium bicarbonate. Fractions are: exchangeable ( $\square$ ), bound to carbonates ( $\square$ ), bound to oxides $(\mathbb{\nabla})$, bound to organic matter $(\otimes)$, residual $(\square)$. Values for stomach contents are those shown in Fig. 2. Neutralized values are means with their standard errors represented by vertical bars for two experiments. For details of procedures, see pp. $438-439$.

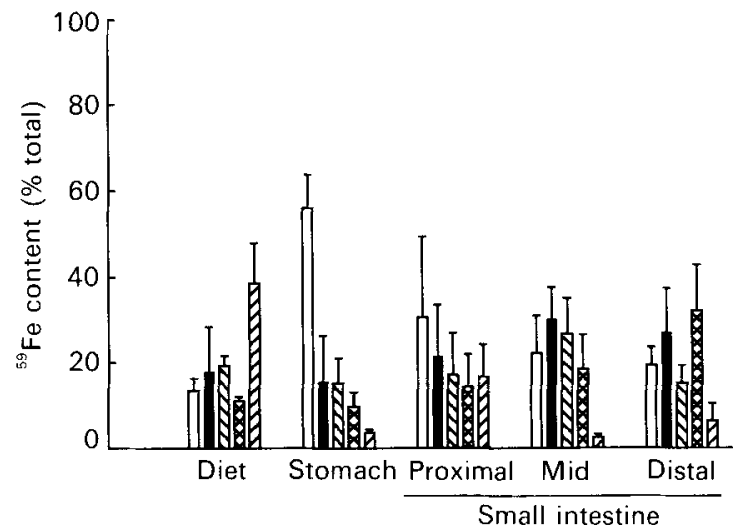

Fig. 5. ${ }^{59} \mathrm{Fe}$ speciation in extrinsically labelled diet. Diet was extrinsically labelled with ${ }^{59} \mathrm{Fe}$, then analysed for ${ }^{59} \mathrm{Fe}$ species. Fractions are : exchangeable $(\square)$, bound to carbonates $(\boldsymbol{\square})$, bound to oxides $(\mathbb{\Xi})$, bound to organic matter ( $\mathrm{B}$ ), residual ( preparations, except for the proximal intestine values, which are for two. For details of procedures, see pp. $438-439$.

et al. 1983; Simpson \& Peters, 1986). The movement of Fe to the carbonate- and oxidebound fractions is consistent with localization of $\mathrm{Fe}-\mathrm{HCO}_{3}$ and $\mathrm{Fe}-\mathrm{OH}^{-}$to these fractions (Fig. 1).

Fig. 3 demonstrates that acid treatment of diet alone cannot reproduce the Fe speciation pattern of the stomach. Even when the $\mathrm{pH}$ of the diet is reduced to a lower value than that observed in the stomach, less $\mathrm{Fe}$ is mobilized to the exchangeable fraction. It is possible that proteolytic enzymes and, perhaps, reducing agents may play an important role in this process in the stomach. In contrast, simple addition of bicarbonate to stomach contents was found to reproduce adequately the changes seen on passage through the proximal small intestine (Fig. 4). This suggests that pancreatic, biliary and mucosal bicarbonate are major determinants of $\mathrm{Fe}$ bioavailability in the rat.

The speciation of ${ }^{59} \mathrm{Fe}$ in extrinsically labelled diet was examined (Fig. 5). This differed from the speciation of endogenous Fe in the diet (Fig. 2), particularly with respect to the 


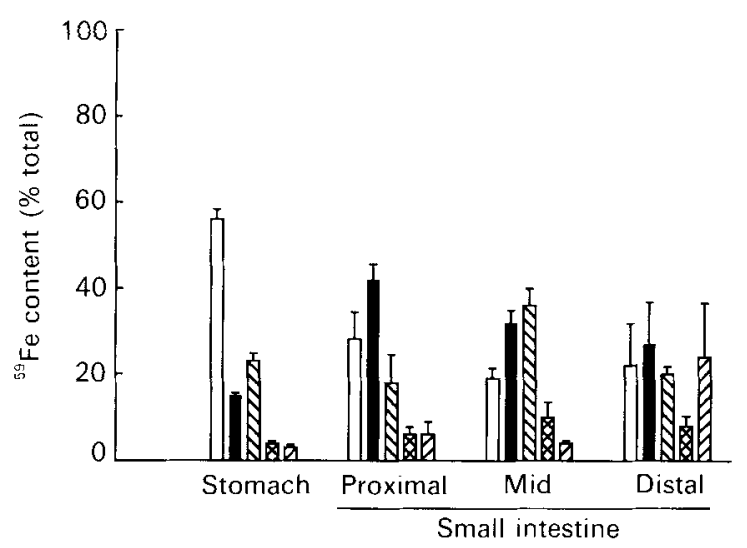

Fig. 6. ${ }^{59} \mathrm{Fe}$ speciation in gastrointestinal contents of rats given ${ }^{59} \mathrm{Fe}$ intragastrically. ${ }^{59} \mathrm{FeCl}_{3}(1 \mu \mathrm{Ci})$ in $1 \mathrm{ml}$ $10 \mathrm{~mm}$-hydrochloric acid was given to four rats by gastric tube and the rats' gastrointestinal contents were

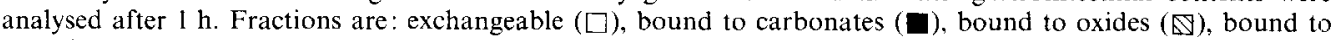
organic matter $(\otimes)$, residual $(\bigotimes)$. Values are means with their standard errors represented by vertical bars. For details of procedures, see pp. $438-439$.

exchangeable fraction. These differences persisted on passage throughout the intestine. When stomach contents were directly labelled in situ with ${ }^{59} \mathrm{FeCl}_{3}$ (Fig. 6), discrepancies between ${ }^{59} \mathrm{Fe}$ and endogenous $\mathrm{Fe}$ speciation were also noted (Fig. 6, cf. Fig. 2). The significance of the differences in extraction was tested by multiple analysis of variance and a significant effect of the differing modes of Fe labelling was demonstrated $(P<0.01)$. A significant difference in the effect of location in the gastrointestinal tract on speciation was also demonstrated $(P<0 \cdot 05)$. Inspection of the univariate $F$ tests demonstrated that the differences were clustered in the carbonate-bound, oxide-bound and residual fractions for the effect of labelling method and in oxide-bound and organic-bound fractions for the interaction of location and labelling method.

\section{DISCUSSION}

The results show that a new technique of selective extraction, based on a soil analysis method (Tessier et al. 1979), can be applied to the speciation of dietary Fe. The technique provides information about chemical forms of Fe present in diets and can be applied to gastrointestinal contents and model digestion experiments.

In the present paper we have used this technique to examine changes in Fe speciation during digestion of a rodent diet by rats. Previous attempts to determine Fe species in the gastrointestinal lumen have been limited (Glover \& Jacobs, 1971; Simpson \& Peters, 1990) and the selective extraction method has the advantage of being applicable to both solids and liquids, thus providing a complete analysis of all the Fe present in both diet and gastrointestinal contents. Other methods of sequential analysis of Fe speciation in diets or foods have concentrated on the water-soluble species, with little analysis of the insoluble species (Shackleton \& McCance, 1936; Hodson, 1970; Lee \& Clydesdale, 1979). The main disadvantage of the method is that several species may be present in a given fraction and further work with model solutions is required to characterize these fractions.

We have further shown the usefulness of the technique in assessing the fidelity with which in vitro models of digestive processes reproduce in vivo changes in $\mathrm{Fe}$ speciation. In particular, while the changes in speciation occurring on passage through the duodenum can be modelled by neutralization with bicarbonate, simple acid-treatment of the diet fails to 
simulate completely the effect of the rat stomach. This justifies the use of pepsin in conjunction with acid, as has been used by several workers (Narasingha Rao \& Prabhavathi, 1978; Miller et al. 1981).

Another capability offered by the technique is the comparison of endogenous dietary Fe speciation with the speciation of extrinsic radio-label. Extrinsic tagging (Cook et al. 1972) has been suggested as a simple method for assessing the bioavailability of food Fe. This technique has been widely used as an alternative to the more difficult intrinsic labelling of food (Lynch, 1984). In the present paper, we investigated the speciation of Fe following extrinsic tagging (i.e. mixing food with a radio-Fe tracer before ingestion) and compared that with the intrinsic non-radioactive-Fe speciation. The findings presented in the present paper show that extrinsic radio-Fe fails to label all the Fe fractions adequately, consistent with suggestions from other studies (Layrisse et al. 1975; Derman et al. 1982) about the limitations of the extrinsic labelling approach to Fe bioavailability.

We have shown that selective extraction may provide a new and useful approach to the study of $\mathrm{Fe}$ species present in diets, in vitro digestions and gastrointestinal contents.

Financial support for this work was provided by the UK Medical Research Council.

\section{REFERENCES}

Becker, G., Korpilla-Schafer, S., Osterloh, K. \& Forth, W. (1979). Capacity of the mucosal transfer system and absorption of iron after oral administration in rats. Blut 38, 127-134.

Brown, E. B. \& Justus, B. W. (1958). In vitro absorption of radioiron by everted pouches of rat intestine. American Journal of Physiology 194, 319-326.

Cook, J. D., Layrisse, M., Martinez-Torres, C., Walker, R., Monsen, E. \& Finch, C. A. (1972). Food iron absorption measured by an extrinsic tag. Journal of Clinical Investigation 51, 805-815.

Derman, D. P., Bothwell, T. H., Torrance, J. D., Macphail, A. P., Bezwoda, W. R., Charlton, R. W. \& Mayet, F. G. H. (1982). Iron absorption from ferritin and ferric hydroxide. Scandinavian Journal of Haematology 29. $18-24$

Fairweather-Tait, S. J. (1987). The concept of bioavailability as it relates to iron metabolism. Nutrition Research 7, 319-325.

Glover, J. \& Jacobs, A. (1971). Observations on iron in the jejunal lumen after a standard meal. Gut 12, 369-371,

Hodson, A. Z. (1970). Conversion of ferric to ferrous iron in weight control dietaries. Journal of Agricultural and Food Chemistry 18, 946-947.

Jacobs, A. \& Greenman, D. A. (1969). Availability of food iron. British Medical Journal 1, 673-676.

Johnson, G., Jacobs, P. \& Purves, L. R. (1983). Iron binding proteins of iron absorbing rat intestinal mucosa. Journal of Clinical Investigation 71, 1467-1476.

Layrisse, M., Martinez-Torrez, C., Renzy, M. \& Leets, I. (1975). Ferritin iron absorption in man. Blood 45, 689-698

Lce, K. \& Clydesdale, F. M. (1979). Quantitative determination of elemental, ferrous, ferric, soluble and complexed iron in foods. Journal of Food Science 44, 549-554.

Lock, S. \& Bender, A. E. (1980). Measurement of chemically-available iron in foods by incubation with human gastric juice in vitro. British Journal of Nutrition 43, 413-420.

Lynch, S. R. (1984). Iron. In Absorption and Malabsorption of Mineral Nutrients, pp. 89-124. New York: Alan R. Liss.

Miller, D. D., Schricker, B. R., Rasmussen, R. R. \& Van Campen, D. (1981). An in vitro method for estimation of iron availability from meals. American Journal of Clinical Nutrition 34, 2248-2256.

Narisingha Rao, B. S. \& Prabhavathi, T. (1978). An in vitro method for predicting the bioavailability of iron from foods. American Journal of Clinical Nutrition 31, 169--175.

Reddy, M. B., Chidambaram, M. V.. Fonseca, J. \& Bates, G.W. (1986). Potential role of in vitro iron bioavailability studies in combatting iron deficiency: A study of the effects of phosvitin on iron mobilisation from pinto beans. Clinical Physiology and Biochemistry 4, 78-86.

Selden, C. \& Peters, T. J. (1986). Separation and assay of iron proteins in needle biopsy specimens of human liver. Clinica Chimica Acta 98, 47-52.

Shackleton, L. \& McCance, R. A. (1936). The ionisable iron in foods. Biochemical Journal 30, 582-591.

Simpson. R. J. \& Peters, T. J. (1986). Mouse intestinal uptake kinetics in vivo. The significance of brush-border membrane vesicle transport in the mechanism of mucosal $\mathrm{Fe}^{3+}$ uptake. Biochimica et Biophysica Acta 856 , $115-122$ 
Simpson, R. J. \& Peters, T. J. (1990). Forms of soluble iron in mouse stomach and duodenal lumen: significance for mucosal uptake. British Journal of Nutrition 63, 79-89.

Tessier, A., Campbell, P. G. C. \& Bisson, M. (1979). Sequential extraction procedure for the speciation of particulate trace metals. Analytical Chemistry 51, 844851 .

Wheby, M. S. \& Crosby, W. H. (1963). The gastrointestinal tract and iron absorption. Blood 22, 416-428. 